Automation and Society

Edited by Howard Boone Jacobson and Joseph S. Roucek. Pp. xiv +553 . (New York : Philosophical Library, 1959.) 10 dollars.

RESOLUTION accepted by the House of A Commons on May 1 in a debate on automation requested the Government to undertake an intensive study of the probable consequences of its introduction and to invite industry to co-operate in effecting the necessary changes with a minimum of hardship to its ernployees. In the debate, which was concerned largely with the bearing of automation on employment, reference was freely made to the report on the technical trends of automation and their impact on management and labour issued by the Department of Scientific and Industrial Research some three years ago and to subsequent inquiries in this field which have been supported by the Department. The present book does not provide the type of report which was visualized in the debate as contributing most decisively to co-operation but the sections dealing with automation and responsibility and with automation and society could assist that task of education or increasing the public understanding upon which alone such co-operation can be firmly based. Apart from the first, in which Mr. P. T. Veillette outlines very clearly the development of the concept of automation, the sections of this book are the composite work of some thirty authors, that on automation applied dealing specifically with its application in some fourteen fields in the United States. The other two sections are of greater interest to British readers, but on the whole they scarcely bring out the social implications any more cleariy than was done in 1950 by the Department of Scientific and Industrial Research's report. The section on automation and society includes a useful dictionary of automation, but the 37 short case-histories of automation in the United States of America and Canada compare poorly with the three case-studies in automation published by Political and Economic Planning in 1957. It is difficult to believe that the book could not have been considerably compressed with great advantage, and the inclusion of brief biographies of contributors does not compensate for the omission of an index or for the scattering of selected bibliographies, some annotated, at the ends of chapters.

R. BRIGHTMAN

\section{Metal Fatigue}

Edited by Dr. J. A. Pope. Pp. xiy +381. (London: Chapman and Hall, Ltd., 1959.) 70s. net.

D EADERS of Nevile Shute will probably be surprised to realize that the unreceptive attitude of engineering designers to Mr. Honey's ideas on fatigue was until fairly recently an authentic picture of the state of affairs in the engineering industry. Several unfortunate aircraft crashes, which were proved to be initiated by fatigue failure, have, however, been in part responsible for a change of heart, and the more forward-looking engineers are now very much exereised by the problem of making allowance for the effects of vibrational stress on their structures. Their task of producing a safe but economical design is not easy ; the amount of reliable data which are available is at present inadequate and, since several uncontrolled variables affect the fatigue life, a statistical approach is essential. The volume under review should be a real help; it reproduces twenty lectures given in the Engineering Department at the
University of Nottingham during a Summer School on the Fatigue of Metals. The professed aim of the editor is "to present to practising engineers the known facts about metal fatigue and its effects on design". This is therefore a book primarily for engineers, although much of it will be read with profit and fascination by metallurgists and others interested in the wayward behaviour of stressed solids.

The work is divided into three main sections: the basic phenomena and, so far as it exists, their explanation ; fatigue properties of engineering materials and components; and fatigue testing of engineering components. The fifteen contributors have produced a readable, clearly presented and useful picture of the state of knowledge in 1955. The engineering designer will draw some comfort from a perusal of the book, particularly from the realization that the problems of fatigue, as they affect him, are being subjected to competent and energetic scrutiny. He will see that already in some directions solid progress has been made, notably in our knowledge of the true stress intensification at cracks and notches, but he may wonder what further developments have taken place in the four years between the compilation of the material for the lectures and the appearance of this book.

K. M. EnTwistie

\section{Principles of Modern Physics}

By Prof. Robert B. Leighton. (International Series in Pure and Applied Physics.) Pp. xii + 795. (London: McGraw-Hill Publishing Company, Ltd., 1959.) $97 \mathrm{~s}$.

$T$ HIS addition to the present series is most welcome. The author has tried to write a book suitable for students of physics in their final year and for specialists in other subjects who require a broad general background. It caters very well for the former group. By assuming a considerable background of mathematics and classical physics a great deal of tedious digression, common in other books, is avoided. The special theory of relativity, once relegated to an appendix, has, at last, achieved its rightful place - the first chapter ; atomic and molecular spectroscopy, so often the major topies, are confined to about seventy pages. More than onethird of the book is devoted to nuclear physics. The book is very comprehensive and up to date. It includes such topics as parity, band theory of solids and X-ray diffraction. Work published as recently as 1958 is referred to. Occasionally, the material becomes too condensed for easy reading, but frequently the exercises are very well designed to supplement the text. Other exercises vary from simple logical extensions of the preceding sections to difficult problems which only a very good student could be expected to solve without assistance. Rationalized M.K.S.A. units are used throughout the book, although some of the formule are also given in what must still be regarded as their more familiar form, and there is a useful appendix of atomic constants in M.K.S.A. units. E. STANXEY

\section{Directory of Nuclear Reactors}

Vol. 1 : Power Reactors. Pp. ix +214 . (Vienna : International Atomic Energy Agency, 1959.) 73.50 schillings ; $21 s$. ; 3.50 dollars.

7 HIS directory makes available the important details of power-reactor projects, throughout the world, which will be producing electric power by the end of 1962 ; reactors with an electric power output 